\title{
Development and Evaluation of Floating and Expanding Gastroretentive Film of Furosemide
}

\author{
Suvarna Chittam*, Ashok Bhosale \\ Department of Pharmaceutics, PDEA'S Seth Govind Raghunath Sable, College of Pharmacy, Saswad, Pune, Maharashtra, INDIA.
}

\begin{abstract}
Objectives: Furosemide is BCS class IV drug which shows pH dependent solubility and permeability. It is very poorly soluble in stomach medium $(0.006 \mathrm{mg} / \mathrm{mL})$ and having high permeability through stomach, but its solubility increases with $\mathrm{pH}$ but it is impermeable through intestine due to its permeation limitation. The objective of this study is to develop integrated floating film of Furosemide to enhance its solubility by increasing gastric residence, by changing $\mathrm{pH}$ so that insoluble furosemide get dissolved, convert from crystalline form to amorphous form so ultimately enhance its bioavailability. Methods: Drug loaded polymeric film prepared by solvent casting method using different polymers such as gelatin and carboxy methyl cellulose sodium (sodium $\mathrm{CMC}$ ), sodium alginate and glycerin as plasticizer, sodium hydroxide as solubility enhancer. The prepared floating films were evaluated for physicochemical parameters such as thickness, weight variation, floating properties, drug content, stability study and in vitro drug release. The drug- polymer interaction was studied by Differential Scanning Calorimetry (DSC) and Fourier transform Infrared (FT-IR).
\end{abstract}

Results: The result of in vitro drug buoyancy and drug release study showed that the floating films were found to be floated up to maximum period of $18.58 \pm 2 \mathrm{hr}$ and maximum $86.78 \pm 0.86 \%$ drug release up to 12 hr. Conclusion: Floating Film enhance the bioavailability of Furosemide by prolonging its duration in the stomach via the floating dosage forms and also enhance its solubility by using hydrophilic polymers and sodium hydroxide as solubility enhancer.

Key words: Floating and expanding film, BCS class IV, Furosemide, Bioavailability.

\section{Correspondence}

Suvarna Chittam

Department of Pharmaceutics, PDEA'S Seth Govind Raghunath Sable, College of Pharmacy, Saswad, Pune, Maharashtra, INDIA.

Phone no: +919420491604

Email: cssgrs@gmail.com

DOI: 10.5530/ijpi.2020.2.33

\section{INTRODUCTION}

Oral route is most agreeable and successfully used route for controlled delivery of drug due to its easy access and the effortless administration, greater pliability in dosage form design, ease of manufacturing and relatively inexpensive. ${ }^{1}$ Although oral controlled drug delivery system (DDS) is most preferable system due to its colossal advantages. However, several physiological hindrance impeding the development process. These encompass lack of ability to restrain and localize the DDS within desired portion of the gastrointestinal (GI) tract and the high variability of gastric emptying process. The emptying process can last from a few minutes to $12 \mathrm{hr}$ depending upon the physiological state of the subject and the nature of formulation. This variability in turn may lead to unforeseeable availability and times to achieve peak plasma levels. Furthermore, the relatively brief gastric residence time in humans (2-3 hr) through the upper part of GIT which is major absorption zone can result in incomplete drug release from the DDS and hence lower bioavailability. Thus, for drugs having narrow absorption window in the GI tract, control of location of a DDS, offers several advantages. These considerations have led to the development of gastro retentive drug delivery system which prolong residence time in stomach and improve their bioavailability. ${ }^{2}$ Gastroretentive system include a number of strategies such as high density systems that is retained in the bottom of the stomach, floating systems that causes buoyancy in gastric fluid, mucoadhesive systems that causes bioadhesion to stomach mucosa , unfoldable, extendible, or swellable systems which limits emptying of the dosage forms through the pyloric sphincter of stomach, superporous hydrogel systems, magnetic systems. ${ }^{3}$ Now, recently combinational techniques used for Gastro Retentive Drug Delivery (GRDDS) like swellable and floating, mucoadhesion and floating, mucoadhesion and swelling, mucoadhesion and high density and floating-pulsatile system. ${ }^{4}$ Among such novel concept, combination of floating with the ability to expand by unfolding and swelling using combination of biodegradable polymers (hydrophilic and hydrophobic) is an alternative strategy to increase gastric residence time. ${ }^{5}$

In the present work an attempt has been made to develop floating film which based on principle of combination of floating and expanding by unfolding and swelling principles.

Furosemide is a loop diuretic that works by decreasing the reabsorption of sodium by the kidneys and mainly used in treatment of hypertension. It is a medication used to treat fluid build-up due to heart failure, liver scarring, or kidney disease. ${ }^{6}$

Furosemide is a weekly acidic drug having pKa 3.9 and having short half-life of $2 \mathrm{hr}$ Oral bioavailability of conventional tablet is 30 to $60 \%$ due to its variable and erratic absorption. ${ }^{7}$ It is a Biopharmaceutical Classification System (BCS) class IV drug with poor aqueous solubility and permeability. It is mainly absorbed from stomach and the upper gastrointestinal tract. ${ }^{8}$ It shows high permeability through stomach because it remain $99.8 \%$ unionize in stomach, but due to its $\mathrm{pH}$ dependent solubility and short gastric empting time it cannot enter in to systemic circulation while in small intestine where it is solubilize but can't absorb through its membrane. Thus furosemide having $\mathrm{pH}$ dependent solubility and permeability. ${ }^{9}$ Furosemide is a candidate for the development of a gastro retentive drug delivery system. Furosemide is better absorbed from gastric region, hence it is need to develop gastro retentive drug delivery system to improve dissolution and residence at absorption site 
of such drug which is challenging and rational. In present investigation, an attempt has been made to enhance the bioavailability of Furosemide by prolonging its duration in the stomach via the floating dosage forms and also enhance its solubility by using hydrophilic polymers and sodium hydroxide which may also convert crystalline form of drug in amorphous form.

\section{MATERIALS AND METHODS}

Furosemide was gifted by (FU) Suleshvari Pharma, Ankaleshwar, Gujarat, Carboxy methyl cellulose sodium (Sodium CMC) was purchased from Fisher scientific, Sodium alginate was gifted by Loba chemie pvt.ltd, Gelatin purchased from John Baker Inc. Hydrochloric acid was gifted by Themis Research Lab, Mumbai. Sodium hydroxide was provided by Poona Chemical Laboratory.

\section{Preparation of Floating and Expanding Film of Furosemide}

Floating films of Furosemide were prepared by solvent casting technique ${ }^{10}$ using gelatin, sodium alginate, sodium CMC in combinations. Ratio of all the ingredients including drug, polymers and excipients were weighed accurately according to the batch formula (Table 1). The film of sodium CMC was prepared by solvent casting method. Drug added in mixture of sodium hydroxide solution and glycerin. This above drug solution added in $4 \%$ aqueous solution of sodium CMC with constant stirring and the resultant mixture was poured in a petri dish and was allowed to dry at room temperature for $48 \mathrm{hr}$. After drying, the films were removed with the help of a sharp blade. It was peeled off (Figure 1a) and cutted into patches of $2 \times 3 \mathrm{~cm}^{2}$. The film of batch F2 was also prepared in similar way only instead of sodium CMC, Sodium alginate was used. The film from batch F3 was prepared using the combination of gelatin with sodium $\mathrm{CMC}$ as a matrix and glycerin as a plasticizer. For preparing film of combination of polymers slight modification was done. First gelatin was dissolved in boiled water and to this gelatin solution glycerin was added as plasticizer and then furosemide and sodium hydroxide solution was added (to adjust the $\mathrm{pH}$ ) so that drug dissolved in solution. This above prepared drug solution added in $4 \%$ sodium CMC solution with constant stirring. For batch F4 same procedure used only instead of sodium CMC, sodium alginate solution used.

\section{Evaluation of formulations}

The formulations were evaluated for following parameters:

\section{Thickness}

Micrometer screw gauge was used to measure thickness of polymeric film at different points which was necessary to ascertain uniformity of the film thickness. ${ }^{11}$

\section{Weight uniformity}

Three films from each batch were randomly selected and weighed individually using digital balance. The results were analyzed for mean weight and standard deviation.

\section{Folding endurance}

A strip of specific area cut evenly and repeatedly folded at the same place till it breaks. The number of times the film could be folded at the same place without breaking is considered as the folding endurance value. It gives idea about toughness of film where lower value of folding endurance indicates brittleness of the film. ${ }^{12}$

\section{In vitro unfolding study}

The prepare polymeric film is folded in two different ways rolling or in zigzag manner and inserted into capsules. The unfolding properties of films containing Furosemide were determined in order to check the ability of the films to stretch back (unfolded) when the gelatin capsule disintegrated in the stomach unfolding property was determined by using a USP dissolution apparatus II (paddle) at $50 \mathrm{rpm}$ in $900 \mathrm{ml} 0.1 \mathrm{~N}$ $\mathrm{HCl}$ solution at $37 \pm 0.5^{\circ} \mathrm{C}$. The films were examined for their unfolding study at certain interval of time. ${ }^{13}$

\section{In vitro buoyancy studies}

The in vitro buoyancy studies were carried out by observing the floating behavior as reported by Rosa. The capsules were placed into the beaker containing $250 \mathrm{ml}$ of $0.1 \mathrm{~N} \mathrm{HCl}$ and also provided with constant stirring speed $50 \mathrm{rpm}$. The floating duration of a film along with the expansion were noted by visual observation. ${ }^{14}$

\section{Drug content}

Film is cut into pieces and put in $100 \mathrm{ml} 0.1 \mathrm{~N} \mathrm{NaoH}$ solution for complete extraction of drug. Solution stirred continuously using a mechanical stirrer and the sample is withdrawn after specific period. Then diluted with $0.1 \mathrm{~N} \mathrm{NaOH}$ solution and the drug content is determined spectrophotometrically at $271 \mathrm{~nm} \cdot{ }^{14,15}$

\section{Swelling index}

Recording the initial weight of a film (W1) and then it was immersed in $0.1 \mathrm{~N} \mathrm{HCl}$ solution at temperature $37 \pm 1^{\circ} \mathrm{C}$ for $360 \mathrm{~min}$ and weighed again (W2). Calculate swelling index using following formula.

Swelling index $(\%)=(\mathrm{W} 2-\mathrm{W} 1) / \mathrm{W} 1 \times 100$

\section{Moisture content}

The prepared films weighed individually and kept in a desiccators containing calcium chloride at room temperature for $24 \mathrm{hr}$. The films were weighed again after a specified interval until they showed a constant weight. The percent moisture content was calculated by using following formula. ${ }^{16}$

$\%$ Moisture content $=[$ Initial weight - Final weight $/$ Final weight $] \times 100$

\section{In vitro dissolution studies}

The drug release study was performed using USP paddle apparatus a double beam UV spectrophotometer (Jasco V-530, Shimadzu Corporation, Japan) at $37 \pm 0.5^{\circ} \mathrm{C}$ and at $50 \mathrm{rpm}$ using $900 \mathrm{~mL}$ of acidic buffer ( $\mathrm{pH}$ 1.2) as a dissolution medium. Capsule containing folded film were placed in a dissolution vessel. $5 \mathrm{~mL}$ of sample solution was withdrawn at predetermined time intervals, diluted suitably and the absorbance of the sample was recorded using UV spectrophotometer at $274 \mathrm{~nm}$. An equal amount of fresh dissolution medium was replaced immediately after withdrawal of the test sample. The \% drug dissolved was calculated using disso software (PCP disso V3). The in vitro release profile was determined. ${ }^{17}$

\section{Fourier transform infrared spectroscopic study (FTIR)}

The interaction between the drug and polymers was studied by using the IR spectroscopy, where in IR spectra of Furosemide, physical mixture of Furosemide with polymers and film were carried out using the $\mathrm{KBr}$ disk method (FTIR-8400S, Shimadzu Corporation, Japan). The scanning range was 400 to $4000 \mathrm{~cm}^{-1}$ and the resolution was $1 \mathrm{~cm}^{-1}$. 


\section{Differential Scanning Calorimetric (DSC) study}

The possibility of any interaction between Furosemide and polymers used in Floating Film formulation was assessed by carrying out the thermal analysis of pure drug, physical mixture of the polymers along with the Furosemide. The thermal behavior of Film also studied using DSC (DSC 30S, Mettler Toledo India Pvt. Ltd., Swizerland) at heating rate of $100^{\circ} \mathrm{C} / \mathrm{min}$. The measurements were performed at a heating range of 40 to $280^{\circ} \mathrm{C}$ under nitrogen atmospheres. ${ }^{18,19}$

\section{RESULTS}

Thickness, folding endurance, in vitro unfolding study of film and moisture content of all batches were found to be in acceptable range.

In-vitro buoyancy study indicated that films containing sodium CMC shows floating 16-18 h. while film containing sodium alginate shows floating time 6-11 hr because alginate shrink in acidic media and get precipitate while sodium CMC swell and form porous hydrogels swelling study indicate that Film F1 (Figure 2) and F3 shows higher swelling index and films get expanded in acidic media.

Moisture content give idea about hygroscopic nature of polymers, excipients and drug. The moisture content was found to be in the range of $1.64 \pm 0.37$ to $5.233 \pm 0.201 \%$ given in Table 2 . It was found that there is negligible amount of moisture present in all films. Film containing polymers in combination with gelatin shows less moisture contain.

In vitro dissolution study of formulations were carried out in acidic buffer pH 1.2 (Table 3). Film F2 shows lowest drug release. While film F1 shows highest drug release. (Figure 3)

The Drug-Excipients interaction Studies were performed in order to confirm the compatibility of drug in presence of excipients. The Drug Excipients Compatibility study include FT-IR and DSC studies.

In FTIR spectra of drug, the characteristic peaks were observed at wave numbers $3400 \mathrm{~cm}^{-1}, 3348 \mathrm{~cm}^{-1}, 3280 \mathrm{~cm}^{-1}, 1674 \mathrm{~cm}^{-1}$ and $1558 \mathrm{~cm}^{-1}$ in the functional group region. FTIR spectra of physical mixtures of polymers with drug and Film retain the characteristic peaks of drug (Figure 4). It indicated that there was no interaction between drug and polymers because the IR spectra of all physical mixtures and IR spectra of film also shows all main peaks of furosemide.

DSC studies revealed that furosemide showed a characteristic sharp endothermic peak at $217.85^{\circ} \mathrm{C}$, indicating the melting point of the drug which is usually associated with decomposition of the drug which shows sharp exothermic peak at $220.70^{\circ} \mathrm{C}$. DSC of pure drug also shows endothermic peak at $272.25^{\circ} \mathrm{C}$ indicating melting endotherm of salumine which is major byproduct after thermal degradation of Furosemide (Figure 5- a). The obtained DSC curves for the physical mixture of drug with polymers shows the same endothermic peak and exothermic peak but it shows little shifted peaks may be due to presence of polymers (Figure 5- b). These peaks did not appear in the thermo gram of film which indicated that the drug was uniformly entrapped in the polymeric matrices of film. But in film the broad endothermic peak at $106^{\circ} \mathrm{C}$ appears may be due to the water associated with film (Figure $5 c)$.

\section{DISCUSSION}

Weight of film and drug content not much deviate from the mean value it may be because of the constant surface area of petridish and constant temperature at which the film was dried and during drying care was taken so that drug not degraded because furosemide is light sensitive and it is quite stable to photodegradation in alkaline solution it was found to be quickly degraded in acidic solution. ${ }^{20}$ All formulation shows weight uniformity in the range of 104-111 because in every formulation equal amount of solvent used in formulation. In case of mixture of two polymers $300 \mathrm{mg}$ gelatin used for $100 \mathrm{mg}$ replacement of sodium alginate or sodium CMC because gelatin solution is very less viscous than solution of these two polymers.

At low $\mathrm{pH}$ values, the carboxyl residues of sodium alginate display the minimum of ionization and hence reduce of hydration. Sodium alginate has property to shrink and stiff at a low $\mathrm{pH}$ value ${ }^{21}$ and hence sodium alginate film shows lower degree of swelling. Film made from combination of gelatin and sodium alginate show slight higher degree of swelling it may be due to presence of gelatin and interaction between gelatin and sodium alginate molecules which form weak intermolecular hydrogen bonds. ${ }^{22} \mathrm{~F} 1$ film of sodium CMC shows higher degree of swelling because of carboxyl groups which protonated. ${ }^{23}$ Film F3 also shows higher degree of swelling because it contain combination of gelatin and sodium CMC which causes formation of gelatin sodium CMC hydrogels which exhibit only a weak ionic character and they didn't show any covalent linkage between polymers. ${ }^{24}$ Addition of sodium hydroxide in film formulation convert crystalline furosemide to its amorphous

Table 1: Formulations of floating and expanding film of furosemide.

\begin{tabular}{ccccccc}
\hline Formulations & Furosemide $(\mathrm{mg})$ & Glycerin & $\begin{array}{c}\text { Gelatin } \\
(\mathbf{m g})\end{array}$ & $\begin{array}{c}\text { Sodium CMC } \\
(\mathbf{m g})\end{array}$ & $\begin{array}{c}\text { Sodium } \\
\text { alginate(mg) }\end{array}$ & $\begin{array}{c}\text { Sodium } \\
\text { hydroxide }\end{array}$ \\
\hline F1 & 200 & 3 drops & - & 400 & - & 7 drops \\
F2 & 200 & 3 drops & - & - & 400 & 7 drops \\
F3 & 200 & 3 drops & 300 & 300 & - & 7 drops \\
F4 & 200 & 3 drops & 300 & - & 300 & 7 drops \\
\hline
\end{tabular}

Table 2: Characteristics of the prepared floating film.

\begin{tabular}{cccccccc}
\hline Sr No & Formulation & $\begin{array}{c}\text { Thickness } \\
(\mathrm{mm})\end{array}$ & $\begin{array}{c}\text { Weight } \\
\text { uniformity }(\mathrm{mg})\end{array}$ & $\begin{array}{c}\text { Drug content } \\
\%\end{array}$ & $\begin{array}{c}\text { Floating time } \\
(\mathbf{h r})\end{array}$ & $\begin{array}{c}\text { Swelling } \\
\text { index (\%) }\end{array}$ & $\begin{array}{c}\text { Moisture } \\
\text { content (\%) }\end{array}$ \\
\hline 1 & F1 & $0.06 \pm 0.05$ & $104.33 \pm 2.49$ & $95.73 \pm 3.96$ & $16.06 \pm 2.28$ & $555.33 \pm 4.10$ & $5.233 \pm 0.20$ \\
2 & F2 & $0.06 \pm 0.01$ & $105 \pm 2.16$ & $94.96 \pm 4.60$ & $10.31 \pm 1.58$ & $86.443 \pm 2.52$ & $5.52 \pm 0.18$ \\
3 & F3 & $0.09 \pm 0.02$ & $110.66 \pm 2.62$ & $95.75 \pm 3.37$ & $18.58 \pm 2.00$ & $595.00 \pm 11.5$ & $2.09 \pm 0.08$ \\
4 & F4 & $0.10 \pm 0.01$ & $111 \pm 2.16$ & $91.79 \pm 1.12$ & $6.43 \pm 1.55$ & $82.433 \pm 7.58$ & $1.64 \pm 0.37$ \\
\hline
\end{tabular}

All values are mean \pm S.D $(n=3)$ 


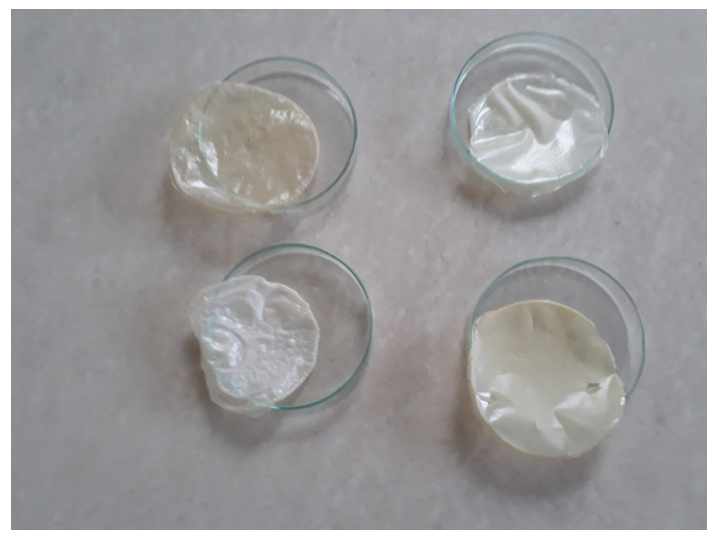

Figure 1a: Formulated film after peel off.

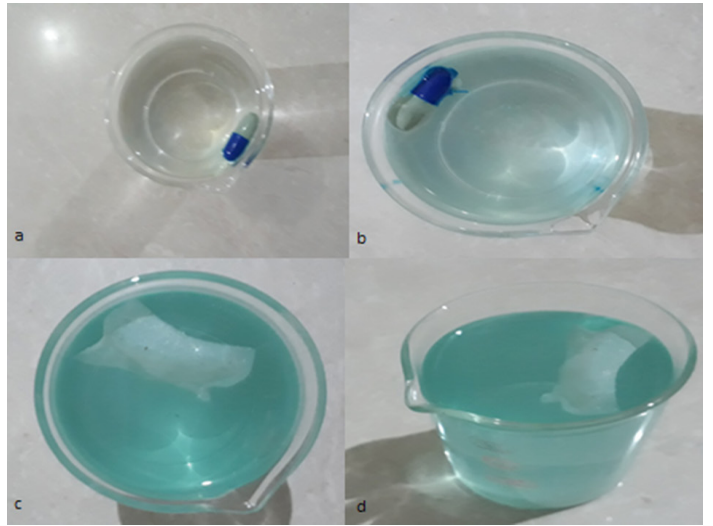

Figure 1 b: Film floated a) after 2 min b) after 30 min c) after $3 \mathrm{~h} \mathrm{d)} \mathrm{after} 6 \mathrm{hr}$.

Table 3: \% In vitro drug release profile of preliminary formulations in acidic buffer pH 1.2.

\begin{tabular}{ccccc}
\hline Time (h) & \multicolumn{4}{c}{${ }^{*}$ Cumulative $\%$ drug release } \\
\hline & F1 & F2 & F3 & F4 \\
\hline 1 & 0.000 & 0.000 & 0.000 & 0.000 \\
2 & $39.571 \pm 1.363$ & $17.431 \pm 1.453$ & $23.943 \pm 0.773$ & $27.431 \pm 4.453$ \\
3 & $50.507 \pm 0.77$ & $24.363 \pm 3.402$ & $37.772 \pm 2.977$ & $39.089 \pm 4.033$ \\
4 & $57.956 \pm 1.652$ & $28.063 \pm 3.203$ & $44.343 \pm 2.162$ & $45.428 \pm 3.124$ \\
5 & $60.600 \pm 2.711$ & $31.550 \pm 1.267$ & $48.850 \pm 2.975$ & $48.042 \pm 2.122$ \\
6 & $64.420 \pm 4.036$ & $34.165 \pm 1.563$ & $54.311 \pm 3.074$ & $53.769 \pm 2.202$ \\
7 & $70.430 \pm 2.293$ & $39.544 \pm 2.135$ & $59.025 \pm 1.444$ & $57.706 \pm 0.972$ \\
8 & $73.796 \pm 1.409$ & $42.356 \pm 0.986$ & $62.796 \pm 1.466$ & $60.267 \pm 1.364$ \\
9 & $76.947 \pm 2.366$ & $44.213 \pm 1.464$ & $66.484 \pm 0.904$ & $64.430 \pm 2.834$ \\
10 & $82.245 \pm 1.858$ & $47.281 \pm 2.511$ & $70.044 \pm 0.492$ & $66.249 \pm 1.450$ \\
11 & $85.012 \pm 0.872$ & $50.132 \pm 3.114$ & $73.250 \pm 1.211$ & $69.163 \pm 1.892$ \\
12 & $86.784 \pm 0.869$ & $50.556 \pm 1.929$ & $79.262 \pm 1.648$ & $72.478 \pm 0.717$ \\
\hline
\end{tabular}

All the values are mean \pm S.D $(n=3)$

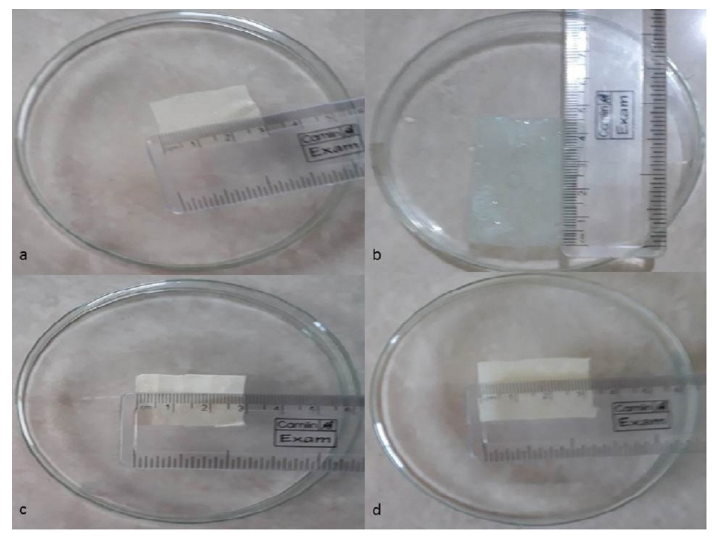

Figure 2: Swelling index of formulation- a) F1 before swelling b) F1 after swelling c) $F 2$ before swelling d) $F 2$ after swelling.

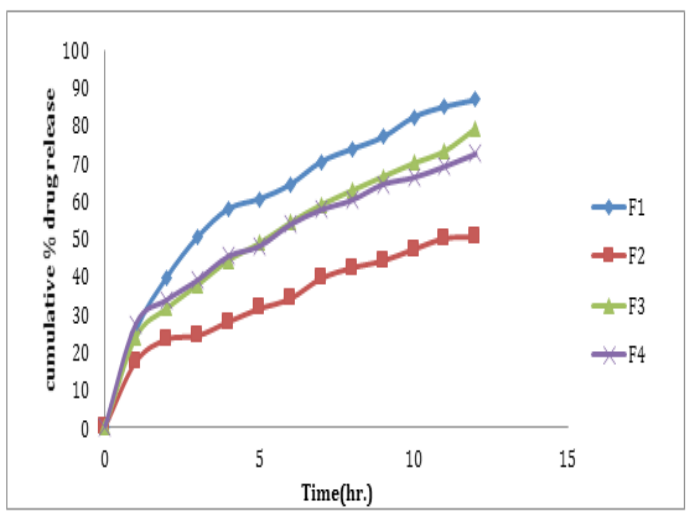

Figure 3: \% In vitro drug release profile of formulations in acidic buffer $\mathrm{PH}$ 1.2

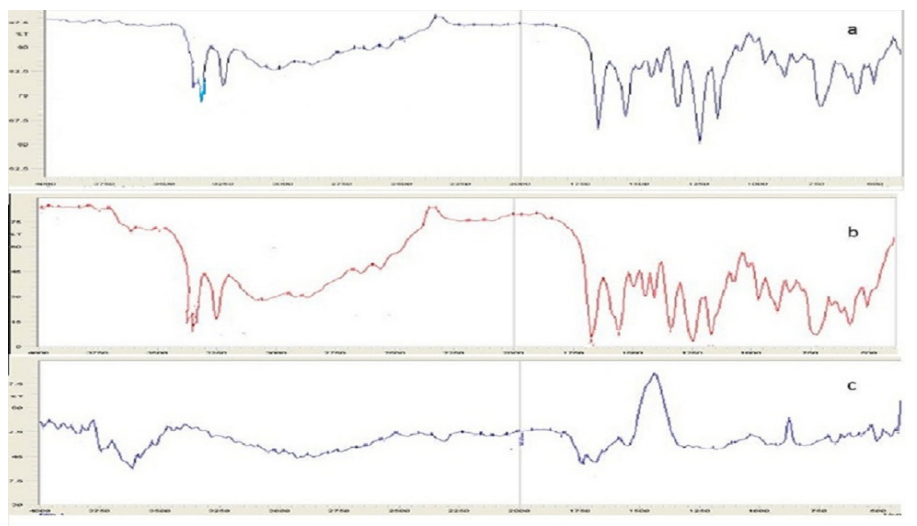

Figure 4: FTIR spectra of a) furosemide b) physical mixture of furosemide and polymers c) film.

sodium salt. The amorphous salt demonstrated an 8- and 20-fold higher intrinsic dissolution rate (IDR) when compared to amorphous and crystalline free acid, respectively. ${ }^{25}$ In all film formulation same amount of sodium hydroxide added. Hence drug release from film depend upon polymers behavior in acidic $\mathrm{pH}$. Film F1shows highest rate of drug release as it contain sodium CMC alone which due to sodium hydroxide first get swell and expand form three dimensional porous hydrogel in acidic media through which drug release at faster rate. while film F3 also shows high drug release as it contain combination of sodium CMC 


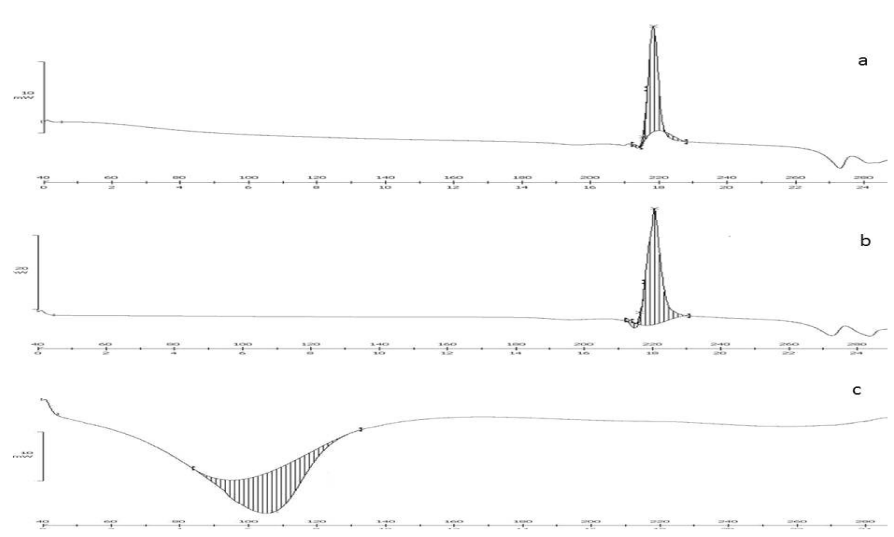

Figure 5: DSC curve of a) Furosemide b) physical mixture c) film.

and Gelatin which form weak intermolecular hydrogen bond. Film F2 containing only sodium alginate shows slowest drug release because it contain sodium alginate which due to sodium hydroxide present in film first it expand and after that it was insoluble and shrank at low $\mathrm{pH}$, so that reduced the medium penetration into the film, resulting the lower drug release rate of formulation. Film F4 contain combination of sodium alginate and gelatin and hence it shows slight higher rate of drug release than film F2 due to combination of gelatin. In vitro dissolution study also indicate that addition of sodium hydroxide in formulation enhance dissolution of drug.

\section{CONCLUSION}

The present study has shown that Floating Film enhance the bioavailability of Furosemide by prolonging its duration in the stomach via the floating dosage forms and also enhance its solubility by using hydrophilic polymers and sodium hydroxide which may also convert crystalline form of drug in amorphous salt form. Formulation F1 contain sodium CMC shows drug release up to $86.78 \%$. Film F3 contain combination of sodium CMC and gelatin were retard drug release but this combination enhancing buoyancy. While film formulation F2 having sodium alginate alone as polymer shows slowest drug release. Combination of gelatin and sodium alginate Film F4 enhance drug release but it decreases its buoyancy. It can therefore be concluded that Film F1 produced in the current study shows promising results in vitro and is a candidate for further studies of the improvement of furosemide bioavailability.

\section{ACKNOWLEDGEMENT}

Authors would like to thank College of Pharmacy, Akluj and College of Pharmacy, Saswad. for providing necessary facilities and support.

\section{CONFLICT OF INTEREST}

The authors declare no conflict of interest

\section{ABBREVIATIONS}

CMC: Carboxy methyl cellulose; GI: Gastrointestinal; DSC: Differential Scanning calorimeter $\mathbf{N a o H}$ : Sodium hydroxide; $\mathbf{H c l}$ : Hydrochloric acid.

\section{REFERENCES}

1. Brahmankar DM, Jaiswal SB. Biopharmaceutics and Pharmacokinetics. $1^{\text {st }}$ ed. A Tretise. Vallabh Prakashan. Delhi. 1995;337-41.

2. Kaur B, Sharma S, Sharma G, Saini R, Singh S, Nagpal M, et al. A review of floating drug delivery system. Asian J Biomed Pharm Sci. 2013;3(24):1-6.

3. Sarojini S, Manavalan R. An overview on various approaches to Gastro retentive dosage forms. Int J Drug Dev Res. 2012;4(1):1-13.

4. Jethara S, Patel M, Patiwala S. Recent Advances, Patent Scenarios and Future Developments on Gastro-Retentive Drug Delivery System: A Patent Overview. Aperito J Drug Design Pharmacol. 2014;1(1):1-12.

5. Leong K, Langer R. Polymeric controlled drug delivery. Adv Drug Deliv Rev. 1988;1(3):199-233.

6. Kabir M, Munir M, Rahman M. Self-emulsifying Drug Delivery System (SEDDS): An Approach for Solubility, Dissolution and Bioavailability Enhancement of Furosemide. Sch Acad J Pharm. 2016;5(7):289-96.

7. Meka L, Kesavan B, Kalamata V, Eaga C, Bandari S, Vobalaboina V, et al. Design and evaluation of polymeric coated minitablets as multiple unit gastroretentive floating drug delivery systems for furosemide. J Pharm Sci. 2009;98(9):212232.

8. Darandale S, Vavia P. Design of a gastroretentive mucoadhesive dosage form of furosemide for controlled release. Acta Pharm Sin B. 2012;2(5):509-17.

9. Patel RC, Keraliya RA, Patel MM, Patel NM. Formulation of furosemide solid dispersion with micro crystalline cellulose for achieve rapid dissolution. J Adv Pharm Technol Res. 2010;1(2):180-9.

10. Verma S, Nagpalb K, Singh SK, Mishra DN. Unfolding type gastroretentive film of Cinnarizine based on ethylcellulose and hydroxypropylmethyl cellulose. Int Biol Macromol. 2014;64:347-52.

11. Shivaraj A, Selvam RP, Mani TT, Sivakumar T. Design and evaluation of transdermal drug delivery of ketotifen fumarate. Int J Pharm Biomed Res. 2010;1(2):427.

12. Deepthi A, Venkateswara RB, Navaneetha K. Formulation and Evaluation of Fast Dissolving Oral Films of Zolmitriptan. Am J Adv Drug Deliv. 2014;2(2):153-63.

13. Hakim B, Mariadi, Karsono. Formulation and in vitro Evaluation of Gastroretentive Drug Delivery System of Antacids using Alginate-Chitosan Films. Int J Pharm Tech Res. 2015;8(9):1-12.

14. Oussama M, Ghenwa I, Mostafa I, Mais A. Assessment of physicochemical properties of furosemide (40mg) tablets marketed in Syria. J Chem Pharm Sci. 2016;9(4):2879-81

15. Fatema K, Mouzam MI, Shahi SR, Shaikh T. Formulation and evaluation of Ar chimedes based novel floating capsule through film formation and retention for drug delivery of levofloxacin. Int J Pharm Sci Res. 2017;8(3):1110-23.

16. Khode PR, Junagade M. Formulation and in-vitro evaluation of gastroretentive mucoadhesive film of famotidine. Int J Res Pharm Chem. 2016;6(3):568-79.

17. Sivaneswari $S$, Karthikeyan E, Chandana P. Novel expandable gastro retentive system by unfolding mechanism of levetiracetam using simple lattice design: Formulation optimization and in vitro evaluation. Bull Fac Pharm Cairo Univ. 2017;55(1):63-72.

18. Ullah M, Karim M, Alam M, Hassan M, Bhuiyan M, Rana M. Formulation and in vitro Evaluation of Unfolding Type Expandable Gastroretentive Film of Enalapri Maleate. Bangladesh Pharm J. 2018;20(2):148-56.

19. Chaulang G, Patel P, Hardikar S, Kelkar M, Bhosale A, Bhise S. Formulation and Evaluation of Solid Dispersions of Furosemide in Sodium Starch Glycolate. Trop J Pharm Res. 2009;8(1):43-51.

20. Bundgaard $H$, Nørgaard T, Nielsen N. Photodegradation and hydrolysis of furosemide and furosemide esters in aqueous solutions. Int J Pharm. 1988;42(13):217-22

21. Chuang J, Huang Y, Lo S, HsuT, Huang W, Huang $S$, et al. Effects of $\mathrm{pH}$ on the Shape of Alginate Particles and Its Release Behavior. Int J Pol Sci. 2017;(1):1-9.

22. Xiao C, Liu H, LuY, Zhang L. Blend films from sodium alginate and gelatin solutions. J Macromol Sci Pure Appl Chem. 2001;38(3):317-28.

23. Basu P, Narendrakumar U, Arunachalam R, Devi S, Manjubala I. Characterization and Evaluation of Carboxymethyl Cellulose-Based Films for Healing of Full-Thickness Wounds in Normal and Diabetic Rats. ACS Omega. 2018;3(10):12622-32.

24. Esteghlal S, Niakousari M, Hashem SMH. Physical and mechanical properties of gelatin-CMC composite films under the influence of electrostatic interactions. Int J Biol Macromol. 2018;114:1-9.

25. Nielsen L, Gordon S, Holm R, Selen A, Rades T, Müllertz A. Preparation of an amorphous sodium furosemide salt improves solubility and dissolution rate and leads to a faster Tmax after oral dosing to rats. Eur J Pharm Biopharm. 2013:85(3):942-51.

Article History: Submission Date : 29-12-2019; Revised Date : 03-02-2020; Acceptance Date : 29-02-2020.

Cite this article: Chittam S, Bhosale A. Development and Evaluation of Floating and Expanding Gastroretentive Film of Furosemide. Int. J. Pharm. Investigation. 2020;10(2):179-83. 